\title{
BREVES CONSIDERAÇÕES SOBRE O PROCESSO ELETRÔNICO E A DEMOCRATIZAÇÃO DO ACESSO À JUSTIÇA
}

\author{
BRIEF CONSIDERATIONS ON THE ELECTRONIC PROCESS AND THE \\ DEMOCRATIZATION OF THE ACCESS JUSTICE
}

\section{Cildo Giolo Jr. ${ }^{1}$ Cláudia de Oliveira Lozada²}

\begin{abstract}
RESUMO - O desenvolvimento tecnológico da informática trouxe inúmeras modificações no meio social, proporcionando também novos delineamentos no campo jurídico. No Brasil, esta evolução informática caminhava incólume até a Emenda Constitucional no 45/2004, que instituiu a duração razoável do processo. Após este marco histórico, o surgimento do processo veiculado de forma eletrônica (Lei $\mathrm{n}^{-}$11.419/2006) viabilizou 0 exercício do acesso à justiça com maior respeito e igualdade entre os jurisdicionados sem o tapume emblemático da sua situação socioeconômica, evidenciando a busca pelo Judiciário com um verdadeiro exercício de cidadania.
\end{abstract}

PALAVRAS-CHAVE - Acesso à justiça. Exercício da cidadania. Processo eletrônico.

ABSTRACT - The development of computer technology has brought many changes in the social environment and also provide new designs in the legal field. In Brazil, this evolution computing walked unscathed by Constitutional Amendment No. 45/2004, which established the reasonable length of proceedings. After this milestone, the onset of the process conveyed in electronic form (Law No. 11.419/2006) allowed the exercise of access to justice with greater respect and equality under jurisdiction without siding emblematic of their socioeconomic situation, highlighting the search for Judiciary with a true exercise of citizenship.

KEYWORDS - Access to justice. Citizenship. Electronic process.

\section{CONSIDERAÇÕES INICIAIS}

\footnotetext{
${ }^{1}$ Pesquisador Doutor em Direito pela UNIMES e em Ciências Jurídicas e Sociais, pela UMSA (Buenos Aires-Argentina), Mestre em Direito Público, pela UNIFRAN (Franca/SP), Especialista em Direito Processual Civil, pela Faculdade de Direito de Franca, Docente da UNIFRAN (Franca/SP), LIBERTAS Faculdades Integradas (São Sebastião do Paraíso/MG) e Faculdade de Direito de Franca e da FAFRAM/FEI (Ituverava/SP). Avaliador do MEC/INEP para Cursos Jurídicos e Advogado. E-mail: cildojr@gmail.com.

${ }_{2}^{2}$ Pesquisadora. Doutoranda pela USP. Especialista em Direito Educacional. Docente do Centro Universitário das Faculdades Metropolitanas Unidas (FMU). Membro do Conselho Nacional de Pesquisa e Pós Graduação em Direito e Membro da Comissão de Direito Processual do Trabalho (OAB, Secção SP). Avaliadora do MEC/INEP para Cursos Jurídicos e advogada. Atua como parecerista em eventos científicos da FEA/USP na área de Contabilidade e Administração. E-mail: clalloz@yahoo.com.br.
} 
As transformações ocorridas pelo desenvolvimento tecnológico, sobretudo, no que diz respeito à informática, não apenas deram novo enfoque às relações humanas, num espaço de inteligência coletiva (LEVY, 2000), de cidades digitais (LEMOS, 2001, 2004) e cibercidadania (MATOS, 1997), mas também proporcionaram novos delineamentos no campo jurídico. A categoria de Direitos criada por Bobbio (1992) em virtude do surgimento dos chamados Novos Direitos estendeu-se doutrinariamente à quinta geração, elencados como direito dos sistemas informatizados e de comunicação:

(...) não é preciso muita imaginação para prever que o desenvolvimento da técnica, a transformação das condições econômicas e sociais, a ampliação dos conhecimentos e a intensificação dos meios de comunicação poderão produzir tais mudanças na organização da vida humana e das relações sociais que se criem ocasiões favoráveis para o nascimento de novas demandas de liberdade e de poderes. (BOBBIO, 1992, p. 33)

A velocidade da informação na Era da Internet, ou como melhor definiu Castells (2002), Era da Informação, afetou consideravelmente a visão que tínhamos do direito à intimidade, do direito autoral, dos contratos que ora passaram para a esfera eletrônica, dos procedimentos judiciais que se tornaram informatizados com a promessa de celeridade.

Juntamente com as inovações, vieram os crimes $^{3}$ cometidos em ambiente virtual, que ainda carecem de legislação no Brasil e a preocupação com a segurança na utilização dos meios eletrônicos.

A esse respeito Ferreira (2005) pontua inclusive que na seara dos crimes da informática, dada a sua extensividade e porque não dizer extraterritorialidade, haja uma cooperação internacional no sentido de reprimir e prevenir tais crimes, estabelecendo-se uma harmonização das normas penais ${ }^{4}$ dos diversos países.

3 No Brasil, destaca-se a aprovação da proposta do senador Eduardo Azeredo (PSDB-MG) que tipifica os crimes cometidos pela internet pela Comissão de Constituição, Justiça e Cidadania (CCJ) em 2008. O projeto é um substitutivo elaborado a partir de três projetos de lei que tramitavam em conjunto: PLC 89/03, PLS 76/00 e PLS 137/00, e em síntese, tipifica entre outros delitos, falsificação de dados ou documentos públicos eletrônicos e o armazenamento de fotos pornográficas de crianças e adolescentes.

${ }^{4}$ O Brasil não é signatário da Convenção de Budapeste que trata da adoção de medidas para combater e punir os crimes cometidos por meio da internet e prevê a troca de informações entre os países-membros, pois não possui até o presente momento, dispositivos penais que 
Por outro lado, o desenvolvimento das funções do Estado, tão acelerado nos últimos anos, tornou insuficientes os meios tradicionais de proteção dos direitos dos jurisdicionados frente ao Judiciário devido ao agigantamento da pobreza. Os instrumentos mais elementares como os reclamos dos juizados especiais, mostraram-se insuficientes para uma devida e rápida solução daqueles anseios.

Dessa forma, não somente a legislação penal teve que avançar para acompanhar as transformações trazidas pela Era da Informação, mas também o Poder Judiciário, que com o advento da Lei no 11.419/2006 estabeleceu a informatização dos procedimentos judiciais.

É necessário realizar um traçado histórico acerca da modernização judicial, a fim de demonstrar o caminho seguido pela evolução da utilização dos meios eletrônicos pelo direito brasileiro, que acarretou a instituição inexorável do processo eletrônico.

Anteriormente, algumas leis foram pioneiras no sentido de introduzir alguns procedimentos eletrônicos, como a Lei ํo 8.245/91 que trata do Inquilinato e que previa a citação via fax em seu artigo 58 , bem como a Lei no 9.800/99, que permitiu que atos processuais fossem encaminhados via fac símile. Antes disto, a Lei o 9.492/97, autorizou o apontamento de protesto de duplicatas mercantis por meio magnético ou de gravação eletrônica de dados. Subsequentes às leis mencionadas foi promulgada a Lei № 10.259/2001, que trata dos Juizados Federais e das comunicações processuais em seu âmbito e que inovou ao tolerar o uso do meio eletrônico no recebimento de petições.

Seguindo os passos do art. 8 da Convenção Americana Sobre Direitos Humanos (Pacto de São José da Costa Rica) ${ }^{5}$, a Emenda Constitucional no 45/2004 alterou o inciso LXXVIII do artigo 5o da Constituição da República Federativa do Brasil de 1988, e tornou-se um marco ao fazer constar que a todos, no âmbito judicial e administrativo, são assegurados a razoável duração do processo e os meios que garantam a celeridade de sua tramitação,

tipificamos crimes cometidos no ambiente virtual, o que torna de extremo relevo o Parecer aprovado pela CCJ em 2008.

5 "Artigo 8. Garantias judiciais. 1. Toda pessoa tem direito a ser ouvida, com as devidas garantias e dentro de um prazo razoável, por um juiz ou tribunal competente, independente e imparcial, estabelecido anteriormente por lei, na apuração de qualquer acusação penal formulada contra ela, ou para que se determinem seus direitos ou obrigações de natureza civil, trabalhista, fiscal ou de qualquer outra natureza". 
prevendo, portanto a razoabilidade do prazo para a entrega da prestação jurisdicional e esta alteração do texto constitucional acolhe com atenção aos anseios da comunidade jurídica por um processo mais rápido e com resultados positivos, no sentido de tornar exequível cumprimento das decisões judiciais e a satisfação dos direitos subjetivos.

Já sobre as luzes da alteração constitucional o Decreto $n^{0}$ 5.450/05 disciplinou o pregão eletrônico, através de lances efetuados pela rede mundial de computadores. A Lei ํㅜ 11.280/2006, que alterou o artigo 154, parágrafo único, do Código de Processo Civil ao estabelecer que:

Os tribunais, no âmbito da respectiva jurisdição, poderão disciplinar a prática e a comunicação oficial dos atos processuais por meios eletrônicos, atendidos os requisitos de autenticidade, integridade, validade jurídica e interoperabilidade da Infraestrutura de Chaves Públicas Brasileira - ICP - Brasil.

Neste mesmo diapasão, a modificação do atual Código de Processo Civil é encargo do Projeto de Lei n.166/2010. Ele foi aprovado no Senado em 15/12/2010 e encaminha para a Câmara dos Deputados onde será rediscutido, revisto e talvez, ainda modificado. Todavia, a versão pesquisada, traz em vários momentos a necessidade da menção na qualificação das partes e de seus representantes, de seu endereço eletrônico para contato, afirmando assim que as intimações dos atos processuais deverão ocorrer por via eletrônica.

Art. 163. Os atos e os termos processuais não dependem de forma determinada, senão quando a lei expressamente a exigir, considerando-se válidos os que, realizados de outro modo, Ihe preencham a finalidade essencial. $\S 1^{\circ}$ Os tribunais, no âmbito de sua competência, poderão disciplinar a prática e a comunicação oficial dos atos processuais por meios eletrônicos, atendidos os requisitos de autenticidade, integridade, validade jurídica e interoperabilidade observada a hierarquia de chaves públicas unificada nacionalmente, nos termos da lei. $\S 2$ 응 Os processos podem ser total ou parcialmente eletrônicos, de forma a permitir que todos os atos e os termos do processo sejam produzidos, transmitidos, armazenados e assinados por meio eletrônico, na forma da lei. § $3^{\circ}$ Os tribunais disponibilizarão as informações eletrônicas constantes do seu sistema de automação, em primeiro e segundo graus de jurisdição, em página própria na rede mundial de computadores, cumprindo aos interessados obter a tecnologia necessária para acessar os dados constantes do mesmo sistema. § 4으 $\mathrm{O}$ procedimento eletrônico deve ter sua sistemática unificada em todos os tribunais, cumprindo ao Conselho Nacional de Justiça a edição de ato que incorpore e regulamente os avanços tecnológicos que forem se verificando. 
Desta maneira, os procedimentos judiciais tal qual o conhecemos, em todas as searas do Direito, vêm sofrendo alterações significativas e traçando novos contornos conceituais para a teoria e doutrina processual. A Lei oㅡ $11.419 / 2006$ em seu artigo $1^{\circ}$ e $\S 1^{\circ}$, respectivamente, assegura $o$ uso do meio eletrônico na tramitação de atos e transmissão de peças processuais (...) aos processos civil, penal e trabalhista, bem como nos juizados especiais, em qualquer grau de jurisdição, visando atribuir celeridade às demandas judiciais.

Isto não poderia ocorrer de forma diferente na Justiça do Trabalho, que tem como especificidade concentrar a prestação jurisdicional aos litígios provenientes das relações individuais e coletivas de trabalho regidas pela CLT, o que infere que tanto empregado como empregadores anseiam por uma decisão justa, célere e eficaz, como pontua Viana (1999, p.47-48):

Quanto mais o processo é eficaz - ou seja, mais célere, econômico, simples e justo - menos o empregado precisa dele: o princípio da tutela se realiza espontaneamente, ou, se preferirmos, pela simples ameaça de sanção, que se faz maior. (...) É por isso que a relação processual sofre as mesmas pressões que afetam o vínculo material. Se o ideal de tutela se enfraquece aqui, também se fragiliza ali afetando todos os princípios que lhe são consequentes.

Um dos exemplos mais notórios da utilização da informática nesta esfera se refere à penhora on line por parte do juízo da execução trabalhista, que contribui para combater a sonegação e protelação do pagamento de dívidas judiciais. Martins (2007, p. 188) assevera a relevância desta espécie de penhora:

Trata-se de providência que se mostrou eficaz na efetivação de direitos sociais trabalhistas, reconhecidos em sentença judicial e até mesmo em acordos homologados em juízo, mas não cumpridos pelo reclamado, muitos deles com execução pendente há vários anos, com o executado na certeza de que ficaria impune.

Ademais, o processo do trabalho, como dito anteriormente apresenta peculiaridades que o diferem do processo civil, tendo como princípios norteadores a oralidade, o informalismo, a concentração, subsidiariedade ${ }^{6}$ e a

\footnotetext{
${ }^{6}$ A esse respeito, Maior se posiciona: "Das duas condições fixadas no artigo 769 , da CLT, extrai-se um princípio, que deve servir de base para tal análise: a aplicação de normas do Código de Processo Civil no procedimento trabalhista só se justifica quando for necessária e eficaz para melhorar a efetividade da prestação jurisdicional trabalhista. (...) $O$ direito processual trabalhista, diante do seu caráter instrumental, está voltado à aplicação de um direito material, o direito do trabalho, que é permeado de questões de ordem pública, que
} 
celeridade, que consiste na redução de fases processuais, recursos e prazos, tornando-o mais dinâmico, a fim de solucionar os litígios em menor tempo possível.

A informatização judicial na esfera trabalhista atribuiu um novo caráter à citada celeridade ${ }^{7}$, que agora se ampara também na utilização de meios eletrônicos. Nesse sentido, este trabalho tem como escopo apresentar uma visão geral sobre a prestação jurisdicional e o acesso à justiça com foco no processo eletrônico.

\section{PRESTAÇÃO JURISDICIONAL E O ACESSO À JUSTIÇA}

Para o cidadão, a demora na entrega da prestação jurisdicional acarreta a ineficácia e inutilidade do próprio provimento judicial. Essa morosidade compromete não só a efetivação do direito buscado, no âmbito da lide, mas também abala a credibilidade do Poder Judiciário, perante a sociedade, para solução dos litígios. Isto ocorre devido ao sentimento geral de impotência da justiça e de limitação do acesso à jurisdição.

O postulado constitucional do acesso à justiça ${ }^{8}$ torna seguro a destinação do serviço judiciário ${ }^{9}$, sendo a verdadeira inafastabilidade do controle jurisdicional da intenção do interessado, devendo esse serviço ter a obrigação de funcionar sem faltas ou defeitos. Baseia-se na segurança da realização do direito objetivo material, tornando indispensável ao magistrado a

exigem da prestação jurisdicional muito mais que celeridade; exigem que a noção de efetividade seja levada às últimas consequências. O processo precisa ser rápido, mas, ao mesmo tempo, eficiente para conferir o que é de cada um por direito, buscando corrigir os abusos e obtenções de vantagens econômicas que se procura com o desrespeito à ordem jurídica".

7 O Projeto de Lei (2006) de autoria do Deputado Edgar Moury, prevê a alteração do art 769 da CLT visando à celeridade processual: "art. 769 § único: $O$ direito processual comum também poderá ser utilizado no processo do trabalho, inclusive na fase recursal ou de execução, naquilo em que permitir maior celeridade ou efetividade de jurisdição, ainda que existente norma previamente estabelecida em sentido contrário."

8 "Art. 5 (...) XXXV - a lei não excluirá da apreciação do Poder Judiciário lesão ou ameaça a direito". (BRASIL. Constituição da República Federativa do Brasil. Promulgada em 5 de outubro de 1988. Atualizada em 19/12/2003. 33. ed. São Paulo: Saraiva, 2004).

9 "Seja nos casos de controle jurisdicional indispensável, seja quando simplesmente uma pretensão deixou de ser satisfeita por quem podia satisfazê-la, a pretensão trazida pela parte ao processo clama por uma solução que faça justiça a ambos os participantes do conflito e do processo. Por isso é que se diz que o processo deve ser manipulado de modo a propiciar às partes o acesso à justiça". (ARAÚJO CINTRA, Antônio Carlos de. PELLEGRINI GRINOVER, Ada. RANGEL DINAMARCO, Cândido. Teoria geral do processo. 8.ed. São Paulo: Revista dos Tribunais, 1991. p.35-36). 
submissão de dados prazos fixados pelo direito formal. Assim, é assegurada pela Constituição cidadã a prestação da tutela jurisdicional, como único meio excepcional de tornar inalterável definitivamente qualquer direito ameaçado. Deve-se reconhecer que esse enunciado constitucional não diz respeito apenas ao direito do jurisdicionado de acesso à justiça e sim um direito de ingresso e retorno de uma prestação jurisdicional efetiva, adequada e tempestiva.

Além do mais, a nossa Constituição é direta ao elevar dentre os seus fundamentos basilare ${ }^{10}$ do artigo $1^{1}$, não só a cidadania, mas, principalmente, a dignidade da pessoa humana. Qualquer ato que a aflija, não encontra proteção no texto constitucional. Afrontando-a o Poder Público afronta o próprio Princípio da Constitucionalidade.

Sendo a jurisdição, também, dever do Estado, no instante em que ela é tardiamente entregue ao cidadão, gera a responsabilidade do causador do dano imposto a quem dela necessita pela demora. Este é o pensamento da Ministra Carmen Lúcia do STF ${ }^{11}$. Como descreve o preceito constitucional que nenhuma lesão de direito individual poderá ser subtraída da apreciação do

\footnotetext{
10 "Art. $1^{\circ} \mathrm{A}$ República Federativa do Brasil, formada pela união indissolúvel dos Estados e Municípios e do Distrito Federal, constitui-se em Estado Democrático de Direito e tem como fundamentos: I - a soberania; II - a cidadania; III - a dignidade da pessoa humana; IV - os valores sociais do trabalho e da livre iniciativa; $V$ - o pluralismo político. Parágrafo único. Todo o poder emana do povo, que o exerce por meio de representantes eleitos ou diretamente, nos termos desta Constituição". (BRASIL. Constituição da República Federativa do Brasil. Promulgada em 5 de outubro de 1988. Atualizada em 19/12/2003. 33. ed. São Paulo: Saraiva, 2004).

11 "O direito à jurisdição é o direito público subjetivo constitucionalmente assegurado ao cidadão de exigir do Estado a prestação daquela atividade. A jurisdição é, então, de uma parte, direito fundamental do cidadão, e, de outra, dever do Estado. (...) Não basta, contudo, que se assegure o acesso aos órgãos prestadores da jurisdição para que se tenha por certo que haverá estabelecimento da situação de justiça na hipótese concretamente posta a exame. Para tanto, é necessário que a jurisdição seja prestada - como os demais serviços públicos - com a presteza que a situação impõe. Afinal, às vezes a justiça que tarda, falha. E falha exatamente porque tarda. Não se quer a justiça do amanhã. Quer-se a justiça de hoje. Logo, a presteza da resposta jurisdicional pleiteada contém-se no próprio conceito do direito-garantia que a jurisdição representa. A liberdade não pode esperar, porque, enquanto a jurisdição não é prestada, ela pode estar sendo afrontada de maneira irreversível; a vida não pode esperar, porque a agressão ao direito à vida pode fazê-la perder-se; a igualdade não pode aguardar, porque a ofensa a este princípio pode garantir a discriminação e o preconceito; a segurança não espera, pois a tardia garantia que lhe seja prestada pelo Estado terá concretizado o risco por vezes com a só ameaça que torna incertos todos os direitos. Esta é a primeira abordagem que se faz presente quando se tecem observações sobre a eficiência da prestação jurisdicional: a melancólica lentidão que a tem marcado. A morosidade da prestação jurisdicional tem frustrado direitos, desacreditado o Poder Público, especialmente o Poder Judiciário, e afrontado os indivíduos". (ROCHA, C. L. A. Princípios constitucionais da administração pública. Belo Horizonte: Del Rey, 1994. p. 35 e 41).
} 
Poder Judiciário. Imaginar como exceção a essa garantia constitucional aquela relativa ao dano cometido no próprio exercício dessa face do poder estatal seria raciocínio incorreto, de vez que tomaria o dano impune e o Estado irresponsável por atos que, afinal, também são seus.

Em outro diapasão Câmara (2007, p. 36), discorrendo sobre o devido processo legal, afirma que:

\begin{abstract}
A garantia de acesso à ordem jurídica justa, assim, deve ser entendida como a garantia de que todos os titulares de posições jurídicas de vantagem possam ver prestada a tutela jurisdicional, devendo esta ser prestada de modo eficaz, a fim de se garantir que a já referida tutela seja capaz de efetivamente proteger as posições de vantagem mencionadas.
\end{abstract}

Desta forma, cumpre ao legislativo, criar um ordenamento jurídico que contenha um processo um funcionamento hábil a entregar a prestação da tutela jurisdicional, cabendo ao judiciário, a capacidade de corresponder de forma esmerada e perfeita o requerimento do jurisdicionado, garantindo ao necessitado de justiça, o seu direito em tempo idôneo.

\title{
3 OBSTÁCULOS AO ACESSO À JUSTIÇA
}

Como um dos principais óbices que devem ser enfrentados para a busca efetiva prestação judicial do Estado ao cidadão é custo do processo. $\mathrm{O}$ processo eletrônico deve diminuir se sobremaneira este preço social.

Cappelletti $(1988$, p.15) enumera como obstáculos a serem transpostos para o fiel acesso à justiça por quem dela necessita como sendo: os gastos judiciais; eis que as custas processuais são muito altas nas sociedades modernas, principalmente naquelas em que a sucumbência impera, onerando por demais aquele que busca a resolução de seu conflito, mas não tem sua demanda atendida. Em outro momento, o mesmo autor afirma que as pequenas causas são obstáculos ao acesso à justiça, pois muitas vezes se tratam de demandas cujo valor é bem menor que os as próprias custas processuais. Por fim, demonstra o estudioso que o longo tempo na solução do litígio causa problemas muitas vezes maiores de que aquele que fez 0 jurisdicionado procurar a justiça. 
Em resposta aos embaraços indicados, o próprio Cappelletti responde com as chamadas ondas (soluções práticas para estes problemas). A primeira onda é a assistência judiciária aos pobres (GOMES NETO, 2005, p. 62). Entre, nós a assistência gratuita permite um maior exercício de cidadania, visto que onera somente o Estado e não o necessitado de justiça e não provido de renda. A segunda onde apresentada é a tutela dos interesses difusos e a acesso à representação em juízo a uma concepção mais ampla de acesso a justiça.

O processo eletrônico induz proveitos como a celeridade, a publicidade e a praticidade e a acessibilidade, facilitando as rotinas de trabalho, otimizando a informação e a comunicação institucional, assim como a prestação de serviços para a sociedade, o que acarreta uma maior eficiência por parte do Poder Judiciário, o que vem de encontro com o dispositivo previsto no art. 37, CF/88. É assim, a mais acertada posição de atendimento às ondas (CAPPELLETTI, 1998), com a intenção de derrubar as dificuldades, democratizando o acesso á justiça.

\section{SOCIEDADE DA INFORMAÇÃO E CELERIDADE JUDICIAL}

São recorrentes as queixas referentes à demora na prestação jurisdicional, seja pela legislação processual cujas lacunas dão margem à mecanismos que permitem a protelação e arrastamento dos processos durante anos, seja pelos meios de tramitação.

Assim, na Sociedade da Informação, é inconcebível o descompasso entre a evolução tecnológica e a prestação jurisdicional. Esta ainda configurase nos moldes passados, apresentando-se engessada em muitos aspectos, o que inviabiliza a sua eficácia. Dessa maneira, a utilização de meios tecnológicos pode tornar a prestação jurisdicional mais plena e justa, permitindo que o acesso à justiça seja mais efetivo. Defende-se inclusive a responsabilidade do Estado pela morosidade na prestação jurisdicional.

Theodoro Júnior $(2004$, p.5) defende a agilização da prestação jurisdicional ao afirmar que: 
(...) o direito processual está comprometido com a rápida e eficiente tutela dos direitos subjetivos lesados ou ameaçados (CF, art.5\%, $\mathrm{XXXV}$ ); nem sempre o itinerário longo e demorado do procedimento ordinário se revela adequado a realizar sua importante missão (justiça tardia quase sempre se traduz em injustiça). Nota-se no direito processual moderno uma forte tendência a criar procedimentos diferenciados para fugir dos inconvenientes da tutela tardonha e propiciar ao jurisdicionado provimento compatível com as necessidades da fiel realização do direito material. (grifo nosso)

Assim, um dos meios para garantir a celeridade da tramitação judicial foi instituído pela Lei n. - 11.419/06, que aborda a informatização judicial, implantando o procedimento judicial eletrônico, cujos primeiros passos foram dados por dispositivos legais citados anteriormente neste trabalho.

De forma sucinta, discorrendo sobre as especificidades da supracitada lei, seu Capítulo I explica termos sobre a informatização do processo judicial; o Capítulo II precisa as regras pertinentes à forma de comunicação dos atos; 0 Capítulo III aborda a forma do processo eletrônico e, ao final, o Capítulo IV, cuidou das modificações em dispositivos do Código de Processo Civil.

Ressaltamos o art. 10 que, no que tange ao acesso ao judiciário, é de suma importância:

Art. 10. A distribuição da petição inicial e a juntada da contestação, dos recursos e das petições em geral, todos em formato digital, nos autos de processo eletrônico, podem ser feitas diretamente pelos advogados públicos e privados, sem necessidade da intervenção do cartório ou secretaria judicial, situação em que a autuação deverá se dar de forma automática, fornecendo-se recibo eletrônico de protocolo.

No âmbito da Justiça no Trabalho esta Lei foi regulamentada pela Instrução Normativa 30/07. Estes significativos passos foram dados por impulso da Emenda Constitucional no 45/04 que alterou a competência, a composição e o funcionamento da Justiça do Trabalho, possibilitando a descentralização, o que ensejou uma prestação jurisdicional célere.

Siqueira Jr (2007, p. 253) designa Sociedade da Informação como a sociedade marcada pelo avanço tecnológico no tratamento da informação. Neste compasso, na Sociedade da Informação, o Direito tem sido amplamente discutido e repensado. Conceitos doutrinariamente pacificados como, por exemplo, o conceito de Jurisdição e de processo, tem sofrido novos 
delineamentos para acompanhar a Era Digital e os novos direitos que dela decorrem:

No campo do Direito Processual foram profundas as alterações. Não faz tanto tempo que os atos processuais eram todos manuscritos. Depois, com o surgimento das máquinas de datilografia, passaram, com algumas exceções, a ser datilografados. Em seguida, com os microcomputadores, a datilografia foi substituída pela digitação. E a tendência atual é a eliminação gradativa do uso do papel, para que os autos se tornem virtuais. (FREIRE, 2007, p.304, grifo nosso)

Para acompanhar a revolução tecnológica que atinge o Direito, Lee Loevinger criou a Jurimetria, que teria como propósito básico a racionalização do Direito mediante a aplicação dos métodos quantitativos de automação à experiência jurídica. (DE LUCCA, 2005, p. 51). Losano, por sua vez, aperfeiçoou conceitualmente as ideias que norteavam a Jurimetria, e propôs a Juscibernética, a qual possibilita estudar (...) os aspectos do Direito e das normas que podem tornar acessíveis aos computadores eletrônicos determinados fenômenos jurídicos. (DE LUCCA, 2005, p. 53)

Dessa maneira, ampliam-se os debates filosófico-jurídicos em torno do Direito na Sociedade da Informação e novas concepções são trazidas no sentido de que a Jurisdição venha a acompanhar a Era da Informação.

Nesse contexto, o prestação da tutela jurisdicional e o trâmite processual são o foco de reiterados debates, na Sociedade da Informação, tendo em vista a morosidade na prestação jurisdicional. Visando atribuir celeridade e economia processual, a Lei 11.419/2006 admitiu o uso de meio eletrônico, em qualquer grau de jurisdição, na tramitação de processos judiciais, comunicação de atos e transmissão de peças processuais. Em seu artigo $1^{\circ}$, $\S 2^{\circ}$, a referida lei define meio eletrônico, transmissão eletrônica e assinatura eletrônica, asseverando, no entanto, para esta última a necessidade de prévio credenciamento junto ao Poder Judiciário.

Em que pesem discussões acerca da nomenclatura, - como nos coloca Almeida Filho (2008, p.117), afirmando que a informatização judicial brasileira trata-se de procedimento - e-doc, processo virtual, processo eletrônico, procedimento eletrônico, o fato é que o Direito Processual sofreu mudanças significativas com a promulgação da referida lei. Prazos processuais, citações, 
intimações, cartas precatórias, rogatórias e de ordem, por exemplo, estão inseridos no contexto eletrônico.

Válido citar a criação de um novo ônus para as partes, no qual consiste em conservar os originais dos documentos digitalizados. Criou-se também o certificado e assinatura digitais. Contudo, debate-se a questão da segurança dos dados que tramitam por meio eletrônico na Justiça.

Tais mudanças alcançaram o Direito do Trabalho. Na Sociedade da Informação, as empresas tornaram-se mais competitivas, implantou-se uma nova governança empresarial e cadeias produtivas globais (PROSCURCIN, 2007). A informatização judicial trazida pela Lei 11.419/2006 também atingiu a esfera trabalhista, procurando tornar a prestação jurisdicional mais ágil. No entanto, coube à Instrução Normativa 30/07 regulamentar o processo eletrônico na Justiça do Trabalho. Anteriormente, por meio da Instrução Normativa 28/2005, O TST havia regulado a prática processual trabalhista por meio eletrônico, no que se refere à protocolização e fluxo de documentos eletrônicos.

Ainda em 2005, o Conselho Superior da Justiça do Trabalho por meio da Resolução no 13, estabeleceu atribuições para o funcionamento da Consultoria Geral de Informática do Conselho Superior da Justiça do Trabalho, visando padronizar e unificar a plataforma tecnológica de informática, utilizada para os procedimentos judiciais ou administrativos.

A Resolução no 48/08 dispôs sobre o modelo de gestão de Projetos Corporativos de Tecnologia da Informação e das Comunicações na Justiça do Trabalho de $1^{\circ}$ e $2^{\circ}$ graus, com destaque para a política e ações de segurança de dados, proteção da informação, armazenamento e backup de dados.

Por sua vez, o Conselho Superior da Justiça do Trabalho, por meio do ato conjunto $n^{\circ}$ 9, de 29 de abril de 2008, instituiu o Sistema Único de Administração Processual (SUAP) da Justiça do Trabalho, no que se refere à informatização.

O TRT/SP implantou o Sistema de Protocolização de Documentos Eletrônicos (SISDOC) em diversas Varas do Trabalho e o Sistema Único de Administração Processual (SUAP). Tais ferramentas permitem 0 préagendamento de audiência, o recurso eletrônico, a carta precatória eletrônica, 
- e-doc (Sistema Integrado de Protocolização e Fluxo de Documentos Eletrônicos na Justiça do Trabalho), e-jus (Sessão Eletrônica de Julgamento), certificação e Diário Oficial Eletrônico. Em 2010, o ministro do TST Milton de Moura França, assinou o Ato Sejud.GP 342/2010 que regulamenta o processo judicial eletrônico no âmbito do Tribunal Superior do Trabalho.

Em agosto de 2010, o CNJ passou a receber petições apenas em formato digital e pretende investir $\mathrm{R} \$ 180$ milhões em equipamentos de informática no Projeto de Modernização Tecnológica do Judiciário para preparar adequadamente os tribunais para que possam trabalhar com 0 processo eletrônico. Em 2007, foi inaugurado o primeiro Fórum Digital do Estado de SP, localizado no bairro da Freguesia do Ó na cidade de SP. Um balanço divulgado pela juíza Teresa Cristina Castrucci Tambasco Antunes da $3^{\text {a }}$ Vara Cível do Fórum Digital de São Paulo, em abril de 2011, revela que a maioria das petições recebidas ainda é em papel, pois há problemas no sistema de informática que afetam diretamente o peticionamento digital, sendo necessário e urgente $\mathrm{o}$ investimento em infraestrutura eletrônica com aprimoramento dos meios digitais, para que de fato a celeridade judicial ocorra.

\section{CONSIDERAÇÕES FINAIS}

Diante dos levantamentos feitos neste trabalho, é salutar afirmar que a propagação tecnológica dos meios de informática trouxe inúmeras modificações no meio social, proporcionando também novos delineamentos no campo jurídico. No Brasil, esta evolução informática caminhava incólume até a Emenda Constitucional n.045/2004, que instituiu a duração razoável do processo. Após este marco histórico, o surgimento do processo veiculado de forma eletrônica (Lei n.․ 11.419/2006) viabilizou o exercício do acesso à justiça com maior respeito e igualdade entre os jurisdicionados sem o tapume emblemático da sua situação socioeconômica, evidenciando a busca pelo Judiciário com um verdadeiro exercício de cidadania.

O que acontecerá a curto prazo será o cumprimento das chamadas medidas urgentes em menor tempo para o jurisdicionado mais necessitado. É preciso lembrar que as defensorias públicas ainda são incipientes na maioria 
dos estados brasileiros ou simplesmente não existem como ocorre no Paraná, onde $\mathrm{o}$ atendimento ao necessitado é feito por advogado nomeado que não viajará até a capital do Estado para defender os interesses de seu representado. Verbi gratia, o cidadão que hoje precisa modificar uma situação através de uma medida cautelar, de um agravo de instrumento (na modalidade de lesão grave ou de difícil reparação) ou mesmo uma sustentação oral recursal e não mora na capital, nem detém recursos para custear a vinda de seu representante até o tribunal acaba ficando restrito ao protocolo integrado, e uma situação emergencial poderá vir a ser alterada em semanas. Com a democratização do processo, todas as partes serão iguais, eis que o mundo virtual não diferencia quem tem ou não melhor condição financeira.

É claro que não era suficiente a mera previsão de tratamento igualitário entre as partes, sem antes dar lhes mínimos meios para peticionar junto ao Judiciário, inclusive com o pagamento de valores equivalente à situação de cada necessitado. Em um Estado que tem a pretensão de ser democrático deve, no mínimo, promover a justiça social, não podendo negar tratamento igualitário a quem busca seus anseios diante da Justiça.

Neste sentido, Lima Filho (2003, p.198) salienta que:

\begin{abstract}
A igualdade preconizada não se coaduna com as diferenças de acesso aos indivíduos. Se as necessidades de tutela jurisdicional forem iguais para ricos e para os pobres, por certo que a discriminação, na abertura dos canais de acesso, atenderá, adversamente, ao princípio da igualdade real, até porque a dignidade da pessoa humana é condição que reveste tanto aos economicamente carentes quanto aos providos de fortuna, razão pela qual a Administração da Justiça deve Ihes atribuir oportunidades idênticas de acesso, inclusive com a criação de condições materiais para que aqueles desprovidos de meios materiais possam efetivamente dispor desse acesso no campo prático.
\end{abstract}

Assim, não é suficiente o acesso à justiça como princípio constitucional, como afirma Gomes (1997, p.180) ${ }^{12}$, é necessário que o Estado tenha e suas mãos um judiciário eficiente e capaz de solucionar os conflitos dos jurisdicionados em tempo razoável e que seja harmonizado com o tipo da lide em tela. Isto para não cairmos prostrados na teoria da legitimação pelo

\footnotetext{
${ }^{12}$ Conflita, por isso mesmo, com o modelo Democrático de Magistratura. Quanto mais se adia a solução de um conflito, mais a Justiça se distancia do modelo ideal". (GOMES, L. F. A dimensão da magistratura. São Paulo: Revista dos Tribunais, 1997. p.180).
} 
procedimento de Luhmann (1980, p.37), em que o acesso à justiça somente legitima e não necessariamente acarreta a solidificação de cidadania.

Entretanto, devemos salientar que tais modificações estruturais dizem respeito à melhorias do acesso ao judiciário e não acesso à justiça. O termo justiça é tão tormentoso e complexo que o próprio Kelsen, em seu estudo sobre o tema, afirmou correr o risco de afirmar o que seria justiça e faltar com a verdade $^{13}$. O acesso à justiça é mais difícil. Deve haver reformas no acesso à justiça no que concerne à própria forma de preparação dos operadores do direito. Essa modificação deve alcançar inclusive a instrução do direito nas faculdades. Para os sectários desta corrente, a mudança deve ser estrutural na própria justiça, bem como na sua forma de acesso, alterando desde a formação do aluno de direito, que acaba por constituir um profissional ineficiente, inabilitado para compreender as exigências da profissão, até às altas cúpulas dos tribunais, que julgam causas que são desinteressantes para a maioria da sociedade, encerrando-se em uma forma de se protelar as aplicações da lei em favor de uma minoria, tornando-se incapaz de levar a justiça ao povo ${ }^{14}$.

Além do mais, aliada à informatização judicial, a questão recursal deve ser revista, de modo a desmantelar o protelamento e manobras que conduzem muitas vezes à prescrição, o que leva o jurisdicionado a não receber efetivamente uma reposta do Poder Judiciário em relação ao seu pedido. Por outro lado, o treinamento dos servidores públicos para que possam operar adequadamente os meios informáticos, é de suma importância, para que não haja óbice e demora nos procedimentos, além de investimentos na melhoria

\footnotetext{
13 "He empezado este ensayo preguntándome qué es la Justicia. Ahora, al concluirlo, sé que no he respondido a la pregunta. Lo único que puede salvarme aquí es la compañía. Hubiera sido vano por mi parte pretender que yo iba triunfar allí donde los más ilustre pensadores han fracasado. Verdaderamente, no sé ni puedo afirmar que es la Justicia, la Justicia absoluta que la humanidad ansía alcanzar. Sólo puedo estar de acuerdo en que existe una Justicia relativa y puedo afirmar qué es la Justicia para mí. Dado que en la Ciencia es mi profesión y, por tanto, lo más importante en mi vida, la Justicia, para mí, se da en aquel orden social bajo cuya protección puede progresar la búsqueda de la verdad. Mi Justicia, en definitiva, es la de la liberdad, de la paz; la Justicia de la democracia, la de la tolerancia." (KELSEN, Hans. ¿Qué es justicia?. Trad. Albert Calsamiglia. Barcelona: Planeta-Agostini: 1993. p.63).

14 "a demora do processo sempre beneficia o réu que não tem razão. Na hipótese em que o réu utiliza o processo para extrair do tempo da justiça alguma vantagem patrimonial, a administração da justiça é evidentemente prejudicada pelo custo do processo". (MARINONI, L. G. Tutela antecipatória, julgamento antecipado e execução imediata da sentença. São Paulo: Revista dos Tribunais, 1997. p.22).
} 
das plataformas eletrônicas, visando otimizar e garantir maior segurança dos procedimentos judiciais eletrônicos.

\section{REFERÊNCIAS}

ALMEIDA FILHO, J. C. A. Processo Eletrônico e Teoria Geral do Processo Eletrônico. 2. Ed. Forense: Rio de Janeiro, 2008.

ATHENIENSE, A. Comentários a Instrução Normativa n. 30/2007 do TST: Regulamentação da Lei do Processo Eletrônico na Justiça Trabalhista. Disponível em: http://www.oab.org.br/oabeditora/users/revista/1211289949174218181901.pdf. Acesso em: 17 abr. 2011.

BOBBIO, N. A Era dos Direitos. Trad. Carlos Nelson Coutinho, Rio de Janeiro: Campus, 1992.

BRASIL. Congresso. Senado. Acrescenta parágrafo único ao art. 769 do Decreto-Lei no 5.452 , de $1^{\circ}$ de maio de 1943, Consolidação das Leis do Trabalho-CLT. Disponível em: http://www.contec.org.br/arquivos/projeto\%20de\%20lei\%201513-2006.pdf.

Acesso em: 17 abr. $2011 .$.

Congresso. Senado. Emenda Constitucional oㅜ 45. Disponível em: http://www.planalto.gov.br/ccivil_03/constituicao/Emendas/Emc/emc45.htm. Acesso em: 17 abr. 2011.

DJU 08.05.2008. Sistema Único de Administração Processual da Justiça do Trabalho - Instituição. Disponível em http://www.trt3.jus.br/cgibin/om_isapi.dll?clientID=103438\&infobase=integratst.nfo\&jump=Ato\%20Conju nto\%20n\%ba\%200009\%2f2008\%2fTST\&softpage=Document42. Acesso em: 17 abr. 2011.

TST. Instrução Normativa 30/07. Disponível em: http://www.trt13.jus.br/corregedoria/index.php?view=article\&catid=53\%3Alegisla cao\&id=288\%3Ainstrucao-normativa-no-30-do-

tst\&option=com_content\&ltemid=69.Acesso em: 17 abr. 2011.

Congresso. Senado. Lei no 11.419/06. Disponível em: http://www010.dataprev.gov.br/sislex/paginas/42/2006/11419.htm. Acesso em: 17 abr. 2011.

CAPPELLETTI, M.; GARTH, B. Acesso à justiça. Porto Alegre: Fabris, 1988.

CINTRA, A. C. A., GRINOVER, A. P., DINAMARCO, C. R. Teoria geral do processo. 8.ed. São Paulo: Revista dos Tribunais, 1991. 
CONJUR. CNJ vai investir $R \$ 180$ milhões em tecnologia. Disponível em: http://www.conjur.com.br/2011-mar-21/cnj-investir-180-milhoes-tecnologiatribunais. Acesso em: 03 maio 2011.

DE LUCCA, N. Títulos e Contratos Eletrônicos: o advento da Informática e suas consequências para a pesquisa jurídica. In: DE LUCCA, N; SIMÃO FILHO, A (Org). Direito e Internet: Aspectos jurídicos relevantes. 2a Ed. São Paulo: Quartier Latin, 2005.

FERREIRA, I. S. A criminalidade informática. In: DE LUCCA, N; SIMÃO FILHO, A (Org). Direito e Internet: Aspectos jurídicos relevantes. $2^{\underline{a}}$ Ed. São Paulo: Quartier Latin, 2005.

FREIRE, R. C. L. Direito fundamental à tutela jurisdicional efetiva na sociedade informacional. In: PAESANI, L. M. (Org). O Direito na Sociedade da Informação. São Paulo: Atlas, 2007.

GOMES, L. F. A dimensão da magistratura. São Paulo: Revista dos Tribunais, 1997.

LAGUARDIA, J. M. G et al. Acesso à justiça e cidadania. São Paulo: Fundação Konrad Adenauer, 2000.

LEMOS, A. Cibercidades. In: LEMOS, A.; PALACIOS, M.(Org.) Janelas do ciberespaço: comunicação e cibercultura. Porto Alegre: Sulina, 2001.

Cibercidades: um modelo de inteligência coletiva. In: LEMOS, André (Org.).Cibercidade: a cidade na cibercultura. Rio de Janeiro: E-papers, 2004.

LÉVY, P. Cibercultura. São Paulo: Editora 34, 2000.

LIMA FILHO, F. C. Acesso à justiça e os mecanismos extrajudiciais de solução de conflitos. Porto Alegre: Fabris, 2003.

KELSEN, H.. ¿Qué es justicia?. Trad. Albert Calsamiglia. Barcelona: PlanetaAgostini: 1993.

LUHMANN, Niklas. Legitimação pelo procedimento. Col. Pensamento Político. Brasília: Editora Universidade de Brasília, 1980.

MAIOR, J. L. S. Reflexos das Alterações no Código de Processo Civil no Processo do Trabalho. In: Revista LTr 70-08/920.

MARINONI, L. G. Tutela antecipatória, julgamento antecipado e execução imediata da sentença. São Paulo: Revista dos Tribunais, 1997.

MARTINS, A. A legislação processual trabalhista e o uso da internet. Revista Mestrado em Direito, Osasco, ano 7, n.1, 2007.

MARTINS, S. P. Direito Processual do Trabalho. São Paulo: Atlas, 2001. 
MATOS, L. M. C. Organizações virtuais. Lisboa: Universidade Nova de Lisboa, 1997.

SIQUEIRA JR, P. H. Habeas Data: remédio jurídico da Sociedade da Informação. In: PAESANI, L. M. (Org). O Direito na Sociedade da Informação. São Paulo: Atlas, 2007.

THEODORO JúNIOR, H. Curso de Direito Processual Civil. 41. ed., Rio de Janeiro: Forense, v.1, 2004.

VIANA, M. T. A proteção social do trabalhador no mundo globalizado. Revista da Associação Nacional dos Magistrados do Trabalho, Brasília, n.37, ago. 1999.

ROCHA, C. L. A. Princípios constitucionais da administração pública. Belo Horizonte: Del Rey, 1994.

Recebido para publicação: 05/08/2011

Aceito para publicação: 19/12/2012 